\title{
The Desocialization of the Courts, Sentencing Decision Support and Plea Bargaining
}

\author{
Andrew Vincent ${ }^{\mathrm{a}, \mathrm{b}}$ and John Zeleznikow ${ }^{\mathrm{a}}$ \\ ${ }^{a}$ School of Information Systems and International Corporate Governance Research \\ Institute, Victoria University of Technology ${ }^{b}$ Greek Studies, La Trobe University, Australia. \\ andrew.vincent1@research.vu.edu.au
}

Judicial decision making in the legal domain is a complex task involving the evaluation large amounts of information, analysing issues, legislation, and precedent as well as assessing feasible options. One of the central and perennial questions of sentencing law and scholarship is how law-makers should pursue an appropriate balance between consistency and individualisation in punishment. In Victoria (Australia) legislatures continue to grant judges considerable discretion in sentencing as distinct from some jurisdictions in America. In these jurisdictions, parliament has, arguably, favoured individualisation over consistency. Even these jurisdictions it is desirable that like cases be treated alike. From a retributivist perspective, a certain measure of consistency is necessary to ensure that offenders are punished in (at least rough proportion) to their culpability and thereby maintain public confidence in the integrity of the criminal justice process. From an economic/utilitarian perspective, consistency enhances certainty of punishment which increases law-makers' ability to pursue optimal levels of deterrence.

Victoria Legal Aid (VLA) is the principal provider of legal aid in Victoria and the largest criminal law practice in the state handling upwards of $80 \%$ of criminal law defense cases. It is thus in VLA's interests to be able to provide sound advice regarding possible sentences especially as a result of guilty pleas. To support this goal we have developed a decision support system to provide advice about possible sentences, so that VLA defense lawyers can make informed decisions about how to best conduct plea bargaining. Most sentencing decision support systems provide statistical sentencing information for judges. Our system is unique in focusing upon the needs of defence counsel.

The Magistrates Court has a surfeit of commonplace cases. These cases can be used to model how magistrates exercise discretion in deciding sentences. There is a growing trend in the criminal justice system to expedite the movement of cases through the system towards final disposition. In Australia plea bargaining and summary disposition of cases are used to accelerate the criminal justice process. This process is responsible for the desocialization of the courts. Desocialization is facilitated by the removal of social information. 
It has been suggested that the process of desocialization of the law, which primarily involves the reduction of social information available to all persons with discretionary power, reduces levels of discrimination. Legal variation is a direct function of social information. Social information is best understood as information that locates individuals within the society they inhabit: racial, economic, cultural, organisational and so on. As the amount of social information increases the more variation is evident, especially with respect to the criminal case. Social information equates to the aggravating and mitigating factors that under the Victorian sentencing regime are to be taken into account when sentencing a criminal. Some social information, for example, that which may be inferred by physical appearance is not to be taken in to account by the judiciary. The modeling that has been conducted (in consultation with domain experts) for the sentencing project, has identified relevant factors that judges and magistrates regularly take into account when sentencing convicted criminals.

The suggestion that legal variation is a direct function of social information means that consistency of outcomes in the sentencing process can be achieved by the removal of all information that places an offender in a social context. Thus consistency of sentence would be achieved based solely on the technical aspects of the case. Sentencing guidelines in the United States require judges to determine the numerical levels associated with the offence of conviction, specific characteristics of the offence (for example, the use of weapon) and the offender's criminal history value. The calculation then reveals an offence level and criminal history category, a sentence is then derived by reference to a sentencing grid. When the Minnesota sentencing guidelines were first established, one of the main purposes was preventing racial, gender, and socioeconomic disparities with respect to sentence. Only a very small amount of social information is allowed to enter the sentencing equation under the United States style of guideline sentencing.

The sentencing decision support system is only the first element of a larger online plea negotiation environment to facilitate negotiation between prosecution and defence (VLA) lawyers. The sentencing system provides a BATNA (Best Alternative to a Negotiated Agreement) for a plea bargain. In an attempt to facilitate the development of online dispute resolution environments [1] have suggested a three-step model combining dialogue tools and negotiation support systems. It is anticipated that the Lodder-Zeleznikow framework can be used profitably to assist in the development of this system by: i). using the sentencing decision support system to provide advice about possible BATNAs; ii). developing a process that enables direct communication and negotiation between the parties which supports interest based communication; iii). Developing a process that provides negotiation support through the use of compensation and trade-off strategies.

The sentencing decision support system provides a way of structuring social information so that a sentence indication can be provided and an informed decision about a plea can be considered.

\section{References}

[1] Lodder, A. and Zeleznikow, J., Developing an online dispute resolution environment: Dialogue tools and negotiation systems in at three step model. The Harvard Negotiation Law Review, 10, 287-338, 2005. 